\title{
Organizational and economic levers to ensure an acceptable level of agro-ecological safety in the context of leadership
}

\author{
Oksana Butrym, Institute of Agroecology and Environmental Management of the National Academy of \\ Agrarian Sciences of Ukraine, 12 Metrological Str., Kyiv, 03143, Ukraine, oksana.butrim@gmail.com \\ ORCID ID: http://orcid.org/0000-0002-2448-6098 \\ Lyudmila Sakharnatska, Uzhhorod National University, Universytets'ka St, 14, Uzhhorod, Zakarpats'ka \\ oblast, 88000, Ukraine, ostapchik81@ukr.net, ORCID ID: http://orcid.org/0000-0002-5863-4917 \\ Nina Palyanychko, Institute of Agroecology and Environmental Management of the National Academy of \\ Agrarian Sciences of Ukraine, 12 Metrological Str., Kyiv, 03143, Ukraine, palianychkoni@gmail.com \\ ORCID ID: https://orcid.org/0000-0003-2230-9634
}

\begin{abstract}
It is proved on the basis of the analysis of statistical reports that the current state of agricultural land use in Ukraine in the production commercial products crop production is not balanced. It was shown that the increase in agricultural production profits is due to the depletion of agro-resource potential without proper implementation of land-based activities. The result of this method of agricultural production on the basis of agricultural land use is high indicators of losses as land resources (the area of degraded soils grows annually by 90 thousand hectares (NATIONAL Report, 2014), more than 30,7\% of lands are eroded), and financial losses (the loss of crop in the medium-earth soils is $40 \%$, and stronglyswollen - 60\%), the consequences of which will be even more disappointing for the following periods. In the process of execution objective of this work from the analysis of the reasons for the formation of increased levels of anthropogenic loading on agroecosystem in Ukraine the systematization of the types of it's impacts has been organized in groups, the key role of agroholdings in this aspect has been determined as the most significant organizational and economic form of implementation of agroindustrial activities. At the same time land use is going based involvement on instruments of lease of agricultural land, due to which the owner of the land plot moving away from the process of land use and minimizing the interest of land users in maintaining an acceptable level of agro-ecological safety, and preferences are given to economic priorities. The correction of the situation is proposed through the strengthening of the use of the potential of organizational and economic instruments and instruments designed to create new economic conditions, which ensures the introduction of a system of scientifically grounded land-use measures, both at the regional level and at a state-level high-value scale. The necessity of introducing an economic turnaround of agricultural land plots with the simultaneous strengthening of the legislative and regulatory framework for the functioning of these processes, the development of the institutional environment and information infrastructure to ensure transparency and public access to information on the state of agroecological safety and qualitative characteristics of soils is substantiated.
\end{abstract}

Keywords: organizational and economic forms of management; land use; agroecological safety; landbased measures, aspects of leadership.

$\begin{array}{lll}\text { Received: 08.12.2020 } & \text { Accepted: 10.01.2021 } & \text { Published: 03.02.2021 }\end{array}$

\footnotetext{
Introduction

Activation of existing organizational and economic forms of land use in the process of production of commodity crop production leads to monopolization in the use of land resources of agricultural purposes, which is one of the causes of negative agro-ecological consequences. The analysis of the characteristics of the land use process proves his unbalanced level, which is confirmed by the volume of land degradation processes in Ukraine, which is being introduced in Ukraine and agricultural sector in particular. Increasing the profits of agro-enterprises of the crop plant due to the exhausting method of using the land resources is contrary to the principles of nature use, declared by the international community when attempting agreements and joint commitments to reduce anthropogenic pressure on the environment. The practice of farming in developed countries confirms the long-term environmental and economic efficiency of the costs of introducing land-based measures, on the basis of which the European Commission has prepared proposals (FUTURE of CAP 2017) for the involvement of various instruments to promote the balanced use of soil. The basic principle of the integrated impact of this system of tools and instruments is directing direct payments to farmers to comply with the basic standards for the environment, food safety and land support in an acceptable agricultural and environmental condition.
} 
Ukraine can become a leader to fulfill obligations under international agreements and the development of national land law is in progress, in particular, a number of Laws "On land protection", "On state control over land use and protection", but the achievement of an acceptable level of agroecological safety as a condition of food security requires the development of theoretical and methodological principles with the further development of applied aspects of their implementation.

\section{Aims}

To analyze the reasons for the formation of the raised levels of anthropogenic loading on agroecosystem in Ukraine and to offer leadership aspects, organizational and economic tools and levers to ensure an acceptable level of agroecological safety.

\section{Materials and methods of research}

The theoretical and methodological basis of the work are general scientific and special research methods that are used to reveal the basic approaches to the introduction of a system of tools and levers of organizational and economic mechanism, designed to provide an acceptable level of agroecological safety: monographic (to identify promising aspects of improving the management of the processes of restoration and conservation of agro-ecological safety ); statistical analysis (for assessing the current state of use of agricultural lands); graphic (for visualization of analytical and statistical materials and obtained research results); a system approach (to substantiate strategic directions of providing agroecological safety); structural-logical (for the establishment of a hierarchy and systematization of anthropogenic influences and loads on the agroecosystem); correlation-regression analysis (for the establishment and measurement of the level of dependence of qualitative indicators regarding the level of agroecological safety and the interactions of anthropogenic nature).

Conducting research is based on the use of the information basis and the international regulatory framework for agricultural production regulation, legislative and normative government acts, materials of the State Statistics Service of Ukraine, the State Service of Ukraine for Geodesy, Cartography and Cadastre, as well as publications of the Institute for the Protection of Soils of Ukraine and other institutions and organizations, including overseas, Internet resources.

\section{Results and discussions}

Characteristics of anthropogenic loading in the production of commodity crop production in Ukraine. The increase in the level of anthropogenic loading on the agroecosystem, which has taken place in Ukraine over the past decade, poses a threat not only to the acceptable level of agroecological safety, but also to the food safety of the state due to the loss of the fertility of the land. Along with the constant increase in agricultural output, there is a steady positive dynamics of the spread of degradation and erosion of soil cover on agricultural lands, loss of humus stock with the following negative consequences for their fertility. So, in the work of V. Kaminsky and V. (Kaminsky\&Saiko 2014, p. 5) it is noted that in Ukraine annual loss of soil is about 600 million tons, the area of degraded soils grows annually by 90 thousand hectares. Almost every third hectare $(30.7 \%)$ is eroded, and the second is deflated dangerously. At the same time, the loss of crop on faint soils (Kaminsky\&Saiko 2014, p. 6), is $20 \%$ medium-washed - 40 and strongly-washed $-60 \%$. Consequently, the use of agricultural land in most cases is not from the point of view of a thriving relation to the soil, as the main wealth of the state and a difficult renewable natural resource, which is confirmed by statistical observations. First of all, pay attention to the spatial-area characteristics of land use. Against the background of agricultural land plots in Ukraine more than $81 \%$ (for comparison - in Germany, this indicator is 32\%, Great Britain - $18.5 \%$, the USA - $20 \%$ agricultural land), during the last decade, the development of ecologically destructive disproportions in the ratio between the categories of land use, which are their constituents. Namely, there is an increase in the area of arable land more than on 100 thousand hectares on the background of the general reduction of the area of agricultural land by 142 thousand hectares. Territorial donor of the expansion of arable land became the area of ecologically stabilizing lands under floods, which decreased by more than 150 thousand hectares and perennial plantations - by 6,6 thousand hectares. (Wadim Strielkowski, Gryshova I.Yu,2018)

Important role in preserving the fertility of the earths is played by the volumes of returning to the soil of nutrients that are cropped. About the total reduction during the period of Ukraine's independence, the volume of introduction of animal hides almost 28 times, in literary sources was emphasized repeatedly. This is due to the low level of profitability of the livestock industry, in the context of almost complete absence of state protection. Additional negative influence on the agrochemical state of the soil environment of the organic component is created by combustion of organic residues in the fields, which is explained by the efforts of land users to reduce the amount of expenses at the technological stage of 
plowing. At the same time, there is a disregard for the prohibition of such actions at the legislative level. These facts demonstrate the need to strengthen the leadership aspects, organizational and economic influence in zemleohoronniy activities.( Wadim Strielkowski, Evgeny Lisin, Inna Gryshova.2016) Ecological-economic characteristics of production of commodity crop production in Ukraine The priorities of farming in the agro-sector are in the economic plane, despite regulatory and legislative requirements for the economical use of agricultural land, as evidenced by statistical data. For example, in Fig. 1 is shown the correlation of trends between volumes of gross production of crop production and the implementation of land protection measures of various types of influence. This is observed a close correlation with humus content in the soil cover on agricultural land.

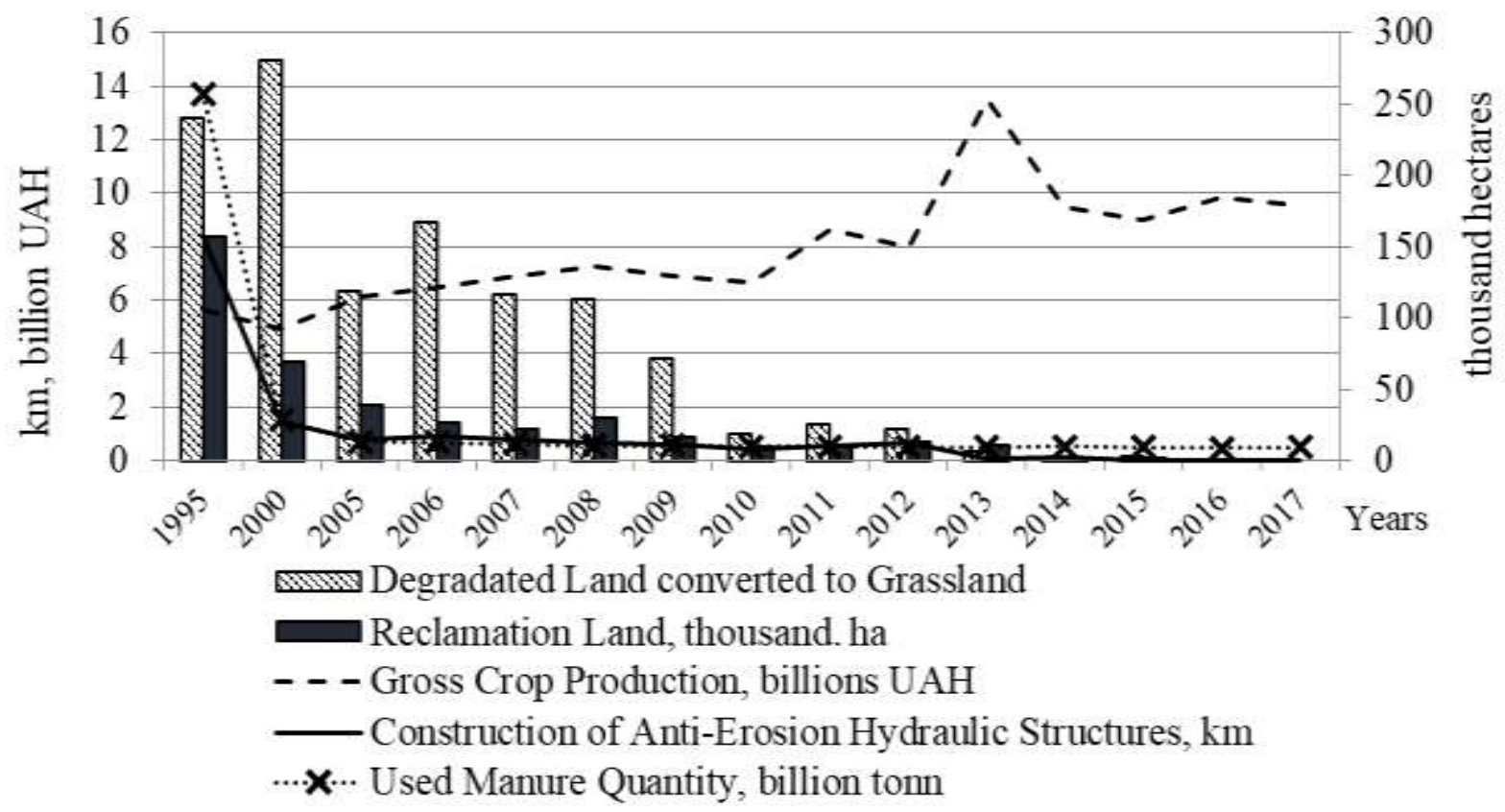

Fig. 1. Characteristics of the use of agricultural land resources in Ukraine Sources of Data: AGRICULTURE of Ukraine, 2016

The highest level of correlation (about 0.9) shows a direct link between humus content (SURVEY of agricultural lands) and volumes of organic fertilizers and the implementation of a complex of land protection measures, among which the most influential was the implementation of measures for the construction of anti-erosion hydraulic structures, land reclamation and the introduction of organic fertilizers, the level of correlation between the volumes of which and the content of humus amounted to 0.9 . Slightly smaller but high flow at the level of 0.7 demonstrate measures to restore ecologically stabilizing lands - the introduction of degraded and polluted arable land. The average impact of the inverse nature is on volumes of direct foreign investments, the maximum values of which during the period of Ukraine's independence took place in the period of 2009-2014 and, according to statistical information, amounted to 700 - 800 million dollars USA. In this context, disproportions in the volumes of commodity products of crop and livestock production in Ukraine are disruptive, with the share of livestock being steadily decreasing and decreased from 38.5\% to 27.3 (AGRICULTURE of Ukraine, 2016) in the period from 2000 to 2016. It should be noted the positive fact that, according to statistical reporting, in 2017, for the first time since 1995, an increase in the volumes of organic fertilizers in relation to the previous year was recorded. Further development of the livestock sector requires an increase in efforts, since an increase in the volume of only the mineral component of fertilizers can not provide an acceptable state of fertility and agroecological safety, which is confirmed by the value of the correlation coefficient of the low level (0.18). Application of increased volumes of mineral fertilizers in the short-term period can positively influence the support of yield indicators, but unbalanced their use contributes to reducing the buffer capacity of soils, the deterioration of their agrochemical and physical characteristics, such as the change of acid-alkaline reaction, consolidation of the soil environment, and eventually leads to to loss of fertility. (Gryshova, I.; Shabatura, T.; Girdzijauskas, S.; Streimikiene, D.; Ciegis, R.; Griesiene, 2019)

In addition, there are negative changes in the structure of crops, acting as an indirect characteristic of compliance with crop rotation. In particular, according to statistical reporting, there is an increase in the areas of the technical group of crops with the simultaneous stable reduction of herbaceous crops (Fig. 2). 
And the general tendency to increase yields creates higher levels of anthropogenic loading on the soil environment and the general state of agroecological safety.( Gryshova, I.; Demchuk, N.; Koshkalda, I.; Stebliuk, N.; Volosova, N., 2019)

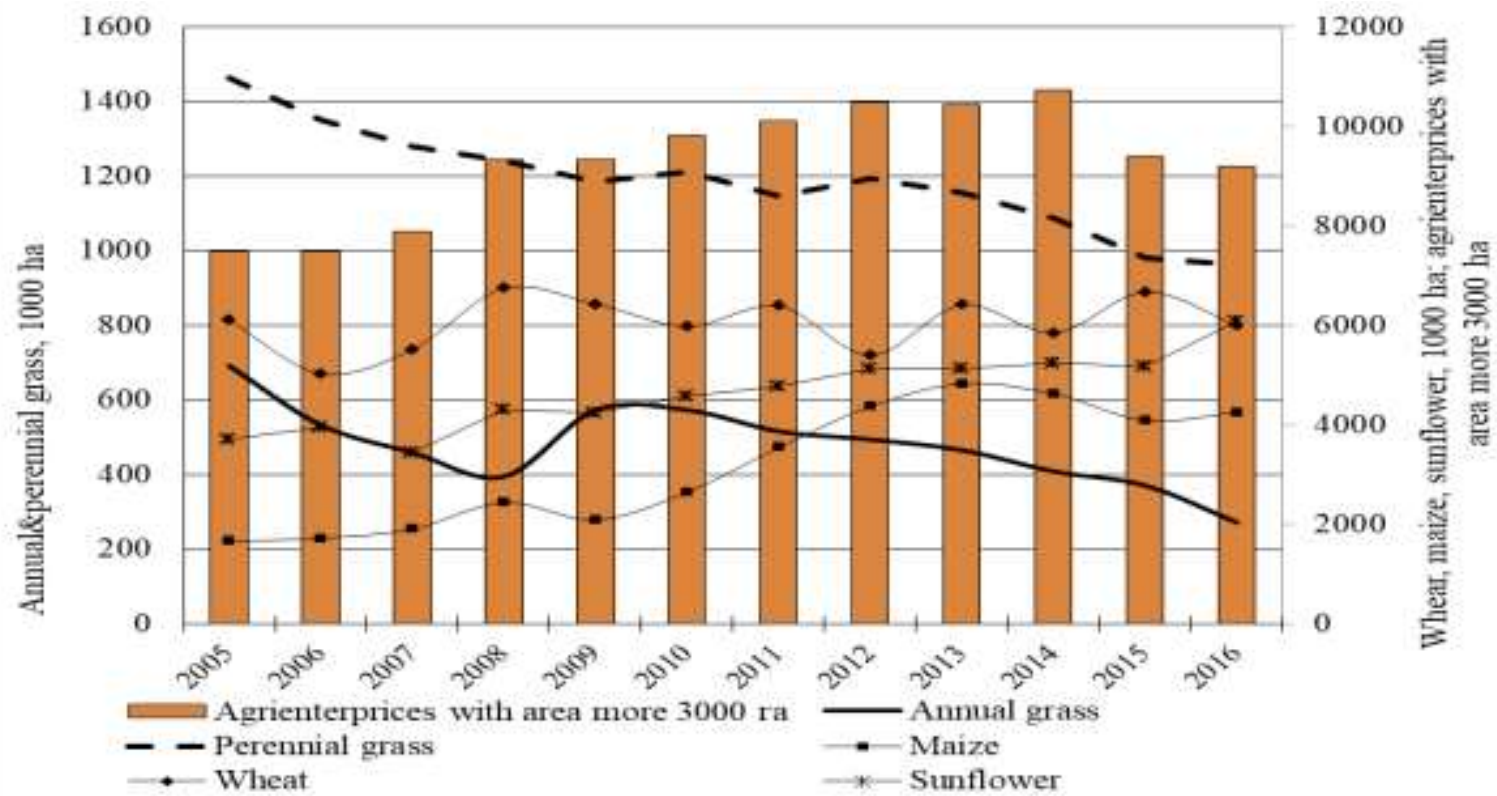

Fig. 2. Dynamics of the area of harvesting of agricultural crops and land bank of the largest agro enterprises, 2000-2015.

Sources of Data: AGRICULTURE of Ukraine, 2016.

Indicative is an increase in crop production per 100 hectares of agricultural land, which according to the State Statistics Service of Ukraine in the measurement of constant prices in 2010 for the period from 2000 to 2017., according the statistic (AGRICULTURE of Ukraine, 2016) increased almost twice (from 370.7 to 715.7 thousand hryvnias). At the same time, the growth rate of plant production for different categories of land users is not the same. The increase in crop production for agricultural enterprises during this period was 2.5 times, and within this group of producers there was a group of farms, in which the growth was almost 7.5 times (from 2.9 to 21.7 billion hryvnias) against an increase of 1.5 times for households (from 47.0 to 70.9 billion hryvnia), by the same sources of information. The growth of economic indicators of agricultural production directly affects the structure of crop sowing, since preference is given to crops with higher profitability rates without sufficient consideration of agrotechnological requirements for compliance with crop rotation. Thus, according to statistical reporting, the level of profitability of grain crops and sunflower produces stably high rates, and in 2017, the profitability of rape production was one of the main places (the third after the cultivation of berries and grapes). Accordingly, the areas and volumes of production of these crops are increasing (Fig. 2), and the largest growth rates are characteristic for agricultural enterprises. At the same time it is necessary to pay attention to the tendency of reduction of volumes of direct investments in agriculture, which according to statistics has decreased from 680 to 505.2 million dollars USA from 2010 to 2016 (AGRICULTURE of Ukraine, 2016).

This brief analysis of statistical information leads to the conclusion that the use of agricultural land resources in Ukraine is carried out not on scientifically grounded basis. Production of marketable crop production in the overwhelming majority is carried out by agricultural enterprises, the main priority of which is the receipt of financial and economic profits against the background of neglect of the need for introduction of land protection measures. This is indirectly confirmed by the dynamics of the share of gross value added of agriculture in the structure of economic activities, according statistics (AGRICULTURE of Ukraine, 2016) which for the period of 2010 - 2016 increased from 8.8\% to 13.7\%, as well as the dynamics of such highly profitable types of products in the structure of export of agricultural products as grain, whose share increased from 24.9\% in 2010 to $39,7 \%$ in 2016; seeds and fruits of oilseeds, the share of which for the specified period fluctuates at the level of $10-12 \%$; fats and oils of animal or vegetable origin - at the level of $26-16 \%$. It should be noted that according to the State Fiscal Service, in the 2017-2018 marketing year, national producers in the foreign market sold 39.4 million tons of grain crops worth $\$ 6.4$ billion. The USA, the largest share of which were: corn - 17.8 billion tons to 2.86 billion dollars. USA; wheat - 17.2 million tons for 2.8 billion dollars USA; barley - 4.3 million tons of 0.64 
billion dollars USA (SEGODNYA, 2018).The specified amount of profits for 2018 is comparable to the amount of financial costs that, according to preliminary estimates (Butrym, 2018, p. 255) necessary for the implementation of a system of land protection measures, the final impact of which is aimed at ensuring an increase in humus stock on agricultural lands. These facts become signs of a trend. According to the report of the Ministry of Agrarian Policy and Food of Ukraine (Trofimtseva, 2018), "... According to the results of January-June 2018, Ukrainian agricultural exports amounted to $\$ 8.6$ billion. The total foreign trade turnover of agricultural products reached $\$ 11.3$ billion, an increase of $3.5 \%$ compared to the same period last year, and represents $23 \%$ of the total foreign trade turnover of Ukraine». The above is a confirmation of the facts of the increase in profits in agricultural production due to the depletion of agro-resource potential.

Based on the described characteristics, we can state that the qualitative state of agroindustries is directly determined by the quantitative parameters of anthropogenic loading, which is created as a result of agricultural production processes and can be submitted according to the groups of influences:

- $\quad$ structural-spatial - determine the ratio of areas between different types of land, methods and characteristics of land use within the boundaries of the land;

- technological - depend on methods and technologies of land use. In the context of addressing the issue of ensuring an acceptable level of agroecological safety, the influence of the specified group of factors is realized through the characteristics of agrotechnologies used for the production of agricultural products, and, above all, the volumes of production of commodity products;

- agrochemicals - are determined not only by the quantitative and qualitative characteristics of fertilizer materials and agrochemical compounds used in agroproduction processes (and not only the part that is directly introduced into the soil, but also have the meaning of compounds used in the storage and transportation of the resulting products, because in the end, their components come to the environment), as well as the importance and ways of their use and storage. This aspect implements the connection of this group of influences with the previous one;

- logical continuation is a group of mechanical influences, which is realized mainly due to the intensity of impacts on the arable layer: the depth of plowing, the mass of agricultural machinery, the area of the wheelbase of the mobile structure, the level of complexity of its use, which determines the total volume of run on the soil cover of the land;

- a separate group can be called organizational and economic influences, which are based on regulatory and legislative provision, which creates economic conditions and organizational forms of agricultural production, functions of planning, control and reporting.

The last group of impacts has a complex, system-generating character and needs to be further explored in order to optimize the anthropogenic load on the agroecosystem and ensure an acceptable level of agroecological safety. Given the steady increase in the share of agricultural enterprises in total production, which increased from $38.4 \%$ to $57 \%$ over the period, it can be argued about the permanent nature of the changes in the structure of organizational and legal forms of management in the agricultural sector of Ukraine. Statistically this is indirectly confirmed by the increase of the land bank of the largest enterprises with an area of more than 10 thousand hectares, in particular, according to state statistics (AGRICULTURE of Ukraine, 2016) there is an increase in the area of land under their treatment by $43.4 \%$ in 2016 relative to 2010 (almost 1 million hectares) due to the reduction of the land bank of enterprises with an area of 1-10 thousand hectares by $18 \%$ over the period indicated. That is, the concentration of the natural resource base of production of commodity agricultural products in a limited number of land users is intensifying and monopolization is increasing as a process of using agricultural land resources and the market of commodity agricultural products. Significant in this context is the fact of the build-up of the land bank by agroholding companies, which by their nature is a form of ownership of the share capital. Under such conditions, the organization of the process of agricultural production, the parent company, has a controlling stake in other companies, manages and controls their activities, thereby integrating them into a single organizational and legal structure with the respective mission and objectives (Barinov \& Skoryk 2011).An example of high rates of dynamics is the fact that in 2010, according to state statistics (AGRICULTURE of Ukraine, 2016) more than ten agroholdings with a land bank were registered for 150 thousand hectares of arable land and more that controlled 330 thousand hectares of arable land, and in general in Ukraine there were more than 50 agricultural holdings (mainly in the Poltava, Cherkasy and Kyiv oblasts), which collectively used about 5 million hectares , or almost $15 \%$ of the area of arable land in Ukraine (Kucher 2010).As of 2016, according to the web-portal "Top 100 Latin American Holders of Ukraine", there are already 115 such companies, and the total amount of their land bank is more than 6.4 million hectares, or almost $20 \%$ of the area of arable land in Ukraine (TOP 100 latifundists 2018). Consequently, the mentioned forms of management develop at a high pace without proper control 
by the state, first of all, on the characteristics of land use and their consequences. It also needs to improve the system of regulatory requirements regarding the quality of soil cover, which is formed as a result of land use, which is a aggravating factor in ensuring an acceptable level of agroecological safety.

Organizational and economic instruments and levers of ensuring an leadership level of agroecological safety in the production of commodity crop production

At the same time, as a result of the alienation of legal landowners from the process of their cultivation actively used organizational and economic instruments of lease. Activation of these forms of land use does not contribute to ensuring an acceptable level of agroecological safety.

The solution of the problem of ensuring an acceptable level of agroecological safety in the production of commodity crop production is achieved by minimizing and mitigating each of the types of impacts. This can be achieved by attracting financial and economic levers and improving organizational and economic approaches to the agricultural production process through deepening, detailing and consolidating the tasks of reproduction and preservation of agro-resource potential in the regulatory and legislative sphere. In Ukraine, at the legislative level, a number of steps have been taken to regulate the process of ensuring an acceptable level of agro-ecological safety, in particular, in addition to the Land Code of Ukraine, the provision of land resources protection is carried out by the Laws of Ukraine "On Land Protection" (2017), "On State Control over Land Protection" (2015), "On Land Management" (2018) etc., by the resolutions of the Cabinet of Ministers of Ukraine, a number of orders from ministries and departments. However, until recently, such important legislative initiatives as "On Stimulating the Development of the Agro-Industrial Complex of Ukraine" (2001), approved by the Government, "On the Conservation of Soils and Protecting Their Fertility" (2017), "On the Turnover of Agricultural Land" (draft) (2016), law on consolidation of land (2018), etc., as well as a number of strategic documents: "The State Target Program for the Development of the Agrarian Sector for the Period until 2021 " (draft) (2018). However, in our opinion, the solution of the problem requires an increased attention to the system of anthropogenic impacts on the soil cover both at the present time and in the future. This justifies the need not only for the coming into force of this list of draft legislative initiatives, but also for strengthening the aspects of reproduction and protection of agro-resource potential and the development of the State Target Program for the balanced use and protection of soil fertility. As shown in Fig. 3, the solution of the problem of ensuring an acceptable level of agroecological safety (AES) plays a central consolidating role in the formation of the organizational and economic mechanism.

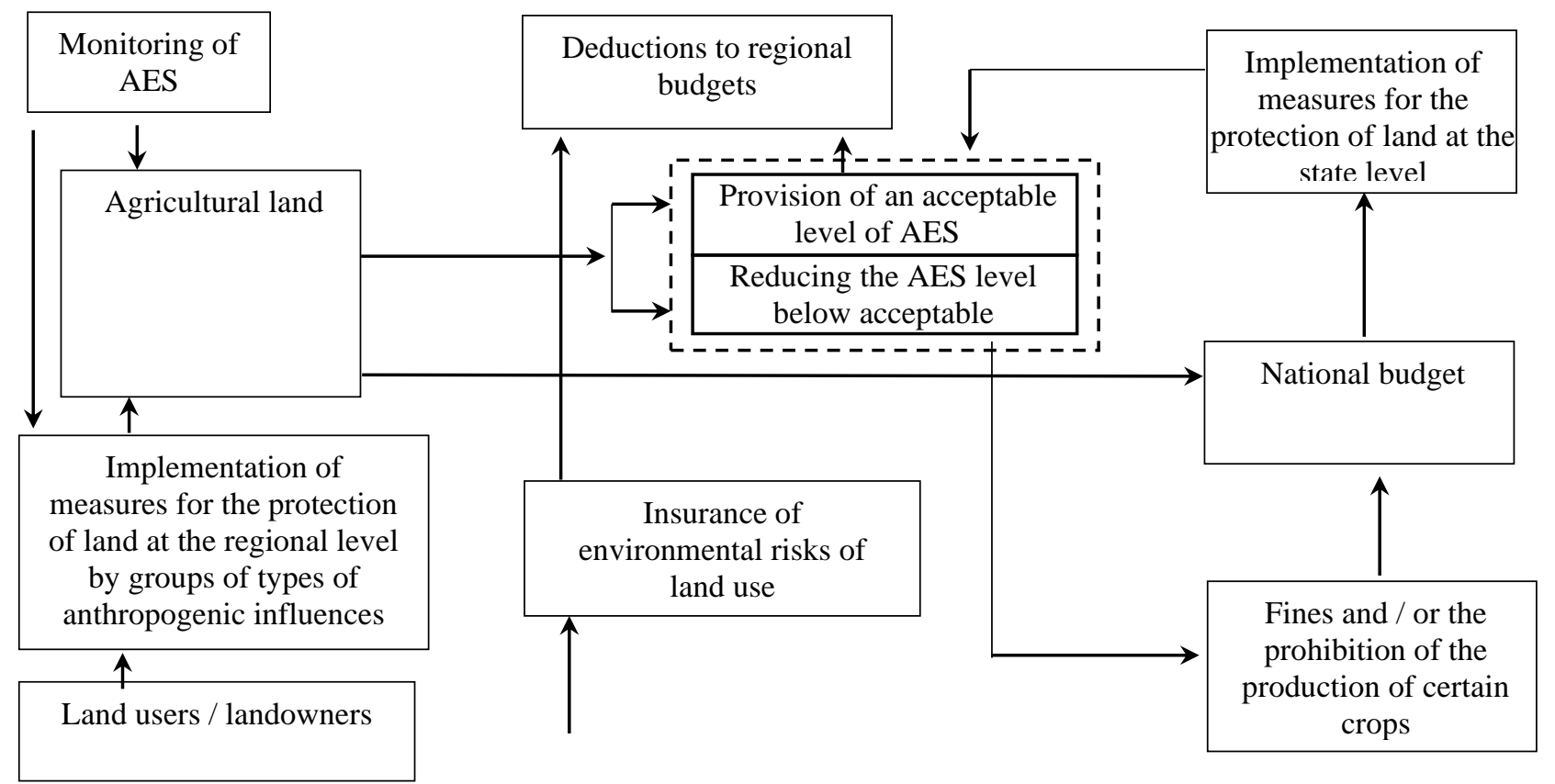

Fig. 3. Organizational and economic mechanism of ensuring an acceptable level of agroecological safety Source: formed on the basis of improvement (O. Butrym, 2018, pp. 270, 283).

Provided that an acceptable level of agroecological safety and successful completion of administrative reform in the state are ensured, an increase in financial allocations at the regional level is ensured. That is, part of the funds paid by land users in the form of taxes or leases, come to regional (local) budgets and limited to the purpose for payment of environmental risk insurance associated with land use. In this case, 
priority should be given to those cases that are related to the introduction of land protection measures. This leverage provides support to small and medium-sized agricultural producers from bankruptcy in achieving the goal of maintaining an acceptable level of agro-ecological safety. In case of loss of an acceptable level of agroecological safety, the land user shall be fined, the amount of payments for which is transferred to the state budget. In the case of the continuation of land use without the introduction of land-based activities, the legislative restriction on the production of commodity products of certain types of crops, which provoke high levels of loads on the soil environment, such as sunflower, corn, and rapeseed, comes into force. The filling of the state budget also comes from the payment of taxes from operations of economic circulation of agricultural land plots, which stipulates the need to lift the moratorium on the introduction of the land market, which has been operating in Ukraine until recently. The use of these funds from the state budget is also limited to the purpose of ensuring an acceptable level of agro-ecological safety, but to finance state measures, that is, with a higher budget. Ensuring objectivity, transparency and targeted use of funds requires coordinated functioning of the monitoring system for the quality of the soil cover of agricultural land, which is the result of anthropogenic influences of various nature. A logical continuation is the need to develop the institutional infrastructure of these processes and information support to ensure transparency and broad public access to reporting on the qualitative characteristics of the state of land and financial resources.

The aim of the formation, implementation and functioning of the organizational and economic mechanism in the field of agricultural land use is aimed at limiting the level of anthropogenic load and stimulating the introduction of scientifically grounded system of land protection measures. As a result, the attraction of a system of incentives and levers of organizational and economic nature will ensure the formation of the latest organizational and economic conditions of management, in which the receipt of excessive profits in the production of commodity crop production due to the depletion of agro-resource potential becomes economically unprofitable. It seems more expedient for a farmer to engage in financial and economic support from insurance payments under the implementation of a system of land protection measures rather than risk financial losses from fines.

Formation and implementation of such updated conditions requires the reformation of the system of interconnections between land users, producers of commodity crop production, on which the organizational and economic mechanism of balanced land use is established. The introduction of such conditions requires strengthening the stage of evaluation and monitoring of the state of land resources, while legislating the following aspects:

- $\quad$ loading standards (by types);

- $\quad$ indicators of soil quality and criteria for an acceptable level of agroecological safety;

- $\quad$ improvement of the monitoring system both by types of anthropogenic influences, and for their effectiveness, that is, on qualitative parameters of soil cover. (Azer Dilanchiev, Gryshova Inna, Rogach Svetlana, Diachenko Oleksii, Batrakova Tetyana, Shabatura Tatyana, 2020)

On the basis of norms and criteria a system of compulsory and stimulating direction is formed: a differentiated approach to fiscal and lease payments, up to the level of restrictions on the volumes of growing of commodity products of certain agricultural crops. On the other hand, in addition to the insurance instrument, it is seen as a successful development of a system of financial, economic and organizational incentives through cheapening of loans, mitigating the tax burden on certain sub-sectors and areas of agricultural production, such as the development of livestock, the expansion of ecological stabilizing lands, observance of scientifically grounded agrotechnological requirements. An important step in this context is the implementation of such a financial and economic instrument as the introduction of economic conversion of agricultural land, which will increase the volume of financial resources from agricultural producers, restrict the monopoly of the largest agricultural holdings both in the field of land use and in the market of agro-products, increase the level of land capitalization resources of agricultural purpose, improvement of the competitive environment. (Dr. Tetiana Tielkiniena, Gryshova Inna, Shabatura Tatyana, Nehodenko Viktoriia, Didur Hanna, Shevchenko Alisa., 2020)

But overall, it becomes clear that the new ideas and developments that can be turned into innovations and their successful commercialization increasingly determine the competitiveness and leadership of the agro-industrial sector in the world. As practice shows, only a small part of innovation is transformed into innovative products and is successfully commercialized through its promotion to interested consumer groups (Gryshova at al. 2019).

\section{Discussion}

The proposed approach to increase the use of theleadership potential of the organizational and economic mechanism and its components and tools is based on the approach taken by the EU countries in organizing the production of commodity crop production. The basic condition for such an approach is the 
economic responsibility of land users for the qualitative characteristics of soil cover on agricultural lands, which ensures an acceptable level of agro-ecological safety. In addition to responsibility, an important role is played by the producers in the fulfillment of the above conditions. Such a situation is ensured by guaranteed financial and economic support from the state of middle and small producers, subject to the requirements of the introduction of scientifically grounded system of land protection measures. On the other hand, in addition to the incentive levers, the favorable effect on ensuring an acceptable level of agroecological safety is created by the system of penalties at its reduction. Attracting the foreign experience of developed countries to solving environmental problems will contribute to ensuring an acceptable state of the environment while maintaining the positive indicators of profitability of agribusiness activity.

\section{Conclusion}

The current state of agroecological safety requires radical changes in the organizational and economic character of the functioning of the crop sector. Over the past decade, national statistics have consistently provided evidence of an increase in the volumes of commodity production of agricultural production in the crop field due to the depletion of agro-resource potential and the excessive use of fertility of agricultural land resources. The solution of the bilateral problem of maintaining an acceptable level of agroecological safety while ensuring positive indicators of profitability of agricultural production requires the formation of new organizational and economic conditions of management. Influence of the updated organizational and economic environment ensures increase of financial and economic responsibility of agricultural producers at the same time their support from the state. But the introduction of such conditions requires an understanding of the legislative field with the simultaneous development of a regulatory framework for the development of assessment scales and parameters for levels of anthropogenic loading on agroecosystems.

\section{References}

National Report on the State of Environment in Ukraine in 2014 (2014). The Ministry of Ecology and Natural Resources of Ukraine: FOP Grin D.S. - 350 p.

Future of CAP: Preserving our soil to protect our food." Editorial. European Commission News. Police, information and service, 05 Dec. 2017. URL: https://ec.europa.eu/info/news/future-cap-preserving-oursoil-protect-our-food en

Kaminsky V., Sayko V. Strategy of optimization of use of land resources in agro industrial production of Ukraine in the context of global sustainable development//News of agrarian sciences. - 2014. - № 3. - P. $5-10$.

Survey of agricultural lands. General information. [In Ukrainian]. Official site of the State Institution 'Soils Protection Institute of Ukraine`: http://www.iogu.gov.ua/pasportizaciya/ahrohimichne-obstezhennyasilskohospodarskyh-uhid/. Accessed 27 Sept 2018.

Agriculture of Ukraine, 2016. Statistical yearbook. State Statistics Service of Ukraine. Kyiv: http://www.ukrstat.gov.ua/.

Ukraine for year earned USD 6.4 bln by corns. Segodnya /Today/. June 22, 2018 . https://www.segodnya.ua/economics/enews/za-god-ukraina-zarabotala-na-zerne-64-mlrd-dollarov-1156225.html

Butrym, O. (2018). Theoretical and methodological foundations of the formation of the domestic carbon market in the context of balanced development of agrosphere in Ukraine: The monograph. - Kyiv: DIA. $356 \mathrm{p}$.

On Land the Protection: Law of Ukraine dated December 18, 2017. No. 962-15. URL: http://zakon5.rada.gov.ua/laws/show/962-15

On State Control over Land Protection: Law of Ukraine dated December 28, 2015. No. 963-IV. URL: http://zakon3.rada.gov.ua/laws/show/963-15

On Land Management: Law of Ukraine dated April 1, 2018. No. 858-IV. URL: http://zakon.rada.gov.ua/ laws/show/858-15?lang=uk

On Stimulating the Development of the Agro-Industrial Complex of Ukraine: Law of Ukraine dated June 26, 2001. No. 2238-III. URL: http://zakon.rada.gov.ua/laws/show/2238-14?lang=en

On the Conservation of Soils and Protecting Their Fertility: Law of Ukraine dated December 18, 2017. No. 962-15. URL: http://zakon.rada.gov.ua/laws/show/962-15?lang=en

On the Turnover of Agricultural Land: Draft of Law of Ukraine dated December 13, 2016. No. 5535. URL: http://w1.c1.rada.gov.ua/pls/zweb2/ webproc4 1?pf3511=60724

On Amending Certain Legislative Acts of Ukraine Regarding the Issue of Collective Ownership of Land, Improving the Land Use Rules in Areas of Agricultural Land, Preventing Raidering and Stimulating 
Irrigation in Ukraine: Law of Ukraine dated Jule 10, 2018. No. 2498-VIII. URL: http://zakon.rada.gov.ua/laws/show/2498-19?lang=en

On Approval of the Concept of the State Target Program for the Development of the Agrarian Sector of the Economy for the period up to 2021: Order of the Cabinet of Ministers of Ukraine dated December 30, 2015 No. 1437-p. Order of Cabinet of Ministers of Ukraine dated February 14, 2018. No. 1437-2015-p URL: http://zakon.rada.gov.ua/laws/show/1437-2015-

\%D1\%80.\%20Accessed $\% 2027 \% 20$ Sept\%202018.?lang=en

Wadim Strielkowski, Gryshova I.Yu (2018) Academic publishing and «predatory» journal. Nauka innov., 14 (1) C.5-12

Gryshova, I.; Shabatura, T.; Girdzijauskas, S.; Streimikiene, D.; Ciegis, R.; Griesiene, I. The Paradox of Value and Economic Bubbles: New Insights for Sustainable Economic Development. Sustainability 2019,11, 6888.

Gryshova, I.; Demchuk, N.; Koshkalda, I.; Stebliuk, N.; Volosova, N. Strategic Imperatives of Managing the Sustainable Innovative Development of the Market of Educational Services in the Higher Education System. Sustainability 2019, 11, 7253.

Wadim Strielkowski, Evgeny Lisin, Inna Gryshova.(2016) Climate Policy of the European Union: What to Expect from the Paris Agreement? Romanian Journal of European Affairs Vol. 16, No. 4, December 2016 Dr. Tetiana Tielkiniena, Gryshova Inna, Shabatura Tatyana, Nehodenko Viktoriia, Didur Hanna, Shevchenko Alisa. LOBBY LEGALIZATION - LEGAL INSTRUMENT FOR ENSURING STATE SUBSIDIES TO LEADERS OF AGRICULTURAL PRODUCERS . JCR. 2020; 7(4): 1679-1683. doi:10.31838/jcr.07.04.274

Azer Dilanchiev, Gryshova Inna, Rogach Svetlana, Diachenko Oleksii, Batrakova Tetyana, Shabatura Tatyana. REMITTANCE LEVELS AND ENTREPRENEURIAL ACTIVITY IN POSTSOVIET COUNTRIES . JCR. 2020; 7(4): 1655-1663. doi:10.31838/jcr.07.04.271 